\title{
Can nasal nitric oxide be a biomarker to differentiate allergic and non-allergic rhinitis?
}

\author{
A. F. Kalpaklioglu, A. Baccioglu and S. A. Yalim*
}

\begin{abstract}
Background: Nasal nitric oxide (nNO), a noninvasive indicator for eosinophilic airway inflammation, has not been adequately studied in different types of rhinitis. The aim of this study was to compare nNO levels between allergic (AR) and non-allergic rhinitis (NAR). Patients were included based on their chronic nasal symptoms. Total nasal symptoms score (TNSS) were evaluated. nNO was measured transnasally with a flow of $5 \mathrm{ml} / \mathrm{s}$ from the nostril with an NO analyzer (NIOX MINO; Aerocrine, Sweden). Results were evaluated as parts per billion (ppb).

Results: Four hundred forty-three patients (277 F/166 M) — 337 with AR (76\%) and 106 with NAR (24\%) —were assessed. Patients with AR had significantly higher TNSS, more severe disease, and longer duration of disease compared to NAR group. Allergic rhinitis had significantly higher nNO levels than NAR (370 ppb vs $290 \mathrm{ppb})(p=$ 0.001). Likewise, significant differences were observed in female gender, in patients with BMl $\geq 25 \mathrm{~kg} / \mathrm{m}^{2}$ and those without sinusitis between the two groups. When $\mathrm{nNO}$ were further evaluated in comorbid asthma, patients with AR w/o asthma had the highest TNSS and had significantly higher nNO level $(p<0.001)$. NAR+A group, with the longest duration of rhinitis, was significantly older and had the lowest nNO level $(p<0.001)$.

Conclusions: This study showed that nNO levels were significantly higher in AR patients than NAR. Although there is no recommended standard threshold for $\mathrm{nNO}$, this study confirmed the utility of $\mathrm{nNO}$ in differentiating $\mathrm{AR}$ and NAR in addition to its known fast and non-invasive advantages.
\end{abstract}

Keywords: Asthma, Allergic rhinitis, Non-allergic rhinitis, Nasal nitric oxide

\section{Background}

Rhinitis is known as an inflammation of the nasal mucosa and estimated to affect almost 200 million people worldwide [1]. This creates indirect costs by loss of work and productivity, as well as a huge burden on society by increasing the needs of medical treatment. Rhinitis can be divided into two different groups, which differ in some features, namely, concomitant allergy (allergic rhinitis $[\mathrm{AR}]$ ) and non-allergic (non-allergic rhinitis [NAR]), according to allergen sensitivity defined by skin prick tests (SPTs) and/or serum-specific IgE [2]. ARIA guidelines classically categorized AR as intermittent and

* Correspondence: alansumeyra@gmail.com

Department of Immunology and Allergic Diseases, Kirikkale University Medical Faculty, Kirikkale, Turkey

\section{Springer Open}

persistent [3] and classify as mild and moderate-severe. Although AR can be diagnosed by allergy tests, there is still no valid test for the diagnosis of NAR. Furthermore, irrelevant allergen test results with rhinitis symptoms in AR patients and local allergic inflammation in NAR patients makes difficult to differentiate rhinitis phenotypes. Failure in the diagnosis of rhinitis types may result to treatment failure. Moreover, recent advances in clinical awareness and treatment of rhinitis may reduce the risk of asthma. Therefore, different rhinitis subtypes should be distinguished in order to reduce symptoms, improve quality of life, and determine an appropriate treatment strategy to prevent comorbidities [4].

Nitric oxide (NO) was primarily identified as an endothelium-derived relaxant through its efficacy as a

(c) The Author(s). 2021 Open Access This article is licensed under a Creative Commons Attribution 4.0 International License, which permits use, sharing, adaptation, distribution and reproduction in any medium or format, as long as you give appropriate credit to the original author(s) and the source, provide a link to the Creative Commons licence, and indicate if changes were made. The images or other third party material in this article are included in the article's Creative Commons licence, unless indicated otherwise in a credit line to the material. If material is not included in the article's Creative Commons licence and your intended use is not permitted by statutory regulation or exceeds the permitted use, you will need to obtain permission directly from the copyright holder. To view a copy of this licence, visit http://creativecommons.org/licenses/by/4.0/. 
vasodilator [2]. Gustafsson et al. was the first that indicated the presence of $\mathrm{NO}$ in exhaled air [5]. Today, measuring fractional exhaled $\mathrm{NO}(\mathrm{FeNO})$ has become a confirmed tool to monitor eosinophilic airway inflammation and response to inhaled corticosteroids in asthma [6]. However, there are controversial reports about the role of NO in nasal inflammation. Some authors showed increased NO levels in patients with AR, whereas other studies reported no differences [6,7]. This could be due to regulatory effect of $\mathrm{NO}$ on cellular functions in response to variable conditions, such as degree of exposure to allergen; presence of infectious inflammation; undertreatment with corticosteroids; confounding factors such as smoking, asthma, rhinosinusitis, and nasal polyps; and finally the occlusion of sinus ostia. Furthermore, there are studies describing the expression of NO synthase (NOS) in human nasal epithelial cells of patients with AR [8]. Kulkarni et al. showed localized immunoreactivity for nasal NOS in healthy human epithelial cells, olfactory mucosa, olfactory receptor neurons, and multiple nerve fibers [9].

In a previous study, we had compared FeNO levels between allergic and non-allergic rhinitis. Patients with AR - with or without asthma-had insignificantly higher FeNO levels compared to patients with NAR (NAR only and NAR+A) and controls, with no difference between genders. Asthmatics had FeNO values significantly higher than non-asthma in the NAR group, whereas accompanying asthma did not affect FeNO levels in the AR group. We found that rhinitis and comorbid asthma were responsible for increased FeNO regardless of atopy [10]. The rationale of this study was the need of an objective tool in the differentiation of AR and NAR. Thus, the objective of this study was to evaluate the role of $\mathrm{nNO}$ in the diagnosis of AR and NAR and the impact of the contributing factors, as well.

\section{Methods}

This cross-sectional and prospective study was performed at Allergy and Immunology Department of a tertiary University hospital. Patients who were diagnosed with rhinitis in the allergy outpatient clinic and whose data were complete in accordance with the study criteria were included in this cross-sectional study. The study was approved by the Institutional Local Ethical Committee. Verbal informed consents were obtained from all participants or their parent in the case of children under 16 years. This study involving volunteers was conducted in accordance with the principles of the Declaration of Helsinki II [11], including human-derived material or data leading to the identification of the individual.

\section{Study groups}

A total of 443 patients as $\operatorname{AR}(n, 337)$ and NAR $(n, 106)$ were enrolled. To be eligible for participation, patients had to meet the following inclusion criteria: age between 16 and $\leq 65$ years; persistent/intermittent rhinitis with or without asthma. Patients with concomitant nasal polyposis, infectious or occupational rhinitis, major structural nasal abnormalities, current sinusitis, and those who were pregnant or lactating, start smoking in the last month, those who have had an infection in the last 4 weeks, known acute or chronic systemic diseases were excluded. Also, lack of data and not accepted to participate in the study were excluded from the study.

\section{Diagnosis of rhinitis and asthma}

Nasal NO was evaluated in a series of consecutive patients referred for persistent rhinitis, with symptoms lasting at least 4 days/week for 4 consecutive weeks. Rhinitis was diagnosed if the patients had a history of at least two of the following symptoms: nasal itching, sneezing, rhinorrhea, and/or nasal congestion, as described by the Allergic Rhinitis and Its Impact on Asthma guidelines [12]. Asthma was diagnosed based on symptoms with positive reversibility test. All patients' asthma status was monitored with the Asthma Control Test (ACT) [13]. Patients were divided into three levels based on their response, whereby those diagnosed with partly controlled and uncontrolled asthma were combined into one group, denoted as "poorly controlled asthma," with "uncontrolled asthma" and "controlled asthma" as the remaining two groups and were enrolled only if they were under regular low dose-inhaled corticosteroid treatment (budesonide or equivalent $<400 \mathrm{mcg} /$ day) and had controlled asthma due to ACT scores (ACT $\geq 20$ ).

The asthma status of all patients was monitored by the Asthma Control Test (ACT). Despite the fact that the ARIA guideline was developed mainly for AR, we classified patients with NAR according to the same definitions to compare the characteristics of these two groups in terms of duration and severity of symptoms.

\section{Study procedure and data collection}

At the screening visit, patients were enrolled due to inclusion and exclusion criteria. If the patient was eligible, inclusion visit was performed for the following data collection. Age, gender, duration of rhinitis, and smoking status were noted. Smokers were defined as participants who reported smoking currently and regularly (at least five cigarettes per day). Body mass index (BMI) was calculated by dividing body weight in kilograms by height in square meters $\left(\mathrm{kg} / \mathrm{m}^{2}\right)$. BMI $\geq 25 \mathrm{~kg} / \mathrm{m}^{2}$ were classified as overweight and obese, those with BMI $<25 \mathrm{~kg} /$ $\mathrm{m}^{2}$ were evaluated in two groups as normal and 
underweight. Patients with a positive SPT (induration of $\geq 3 \mathrm{~mm}$ in diameter) and/or specific $\operatorname{IgE}(\geq 0.35 \mathrm{kU} / \mathrm{L})$ against aeroallergens consistent with the complaints were defined as $A R$, and those with negative prick test and specific IgE were defined as NAR. Patients with asthma in the AR and NAR groups were further analyzed as subgroups of AR+A and NAR+A.

Nasal symptoms were evaluated on a 4-point scale from 0 to 3 (Table 1) [14]. Total nasal symptom score (TNSS) was calculated as the sum of four symptoms with a range of 0-12.

\section{Nitric oxide measurement}

Nasal NO was measured using a nasal cannula inserted into the nostril. The subject was then asked to take a deep breath, close his mouth, and hold his breath. The breath was not given at least for $30 \mathrm{~s}$ than given throughout the nose slowly. The subjects were asked to repeat this maneuver three times, and the best of these measurements was accepted as NO level in the nose. The ambient NO level was recorded before each maneuver. The patients were excluded if the subjects could not hold their breath or the presence of nasal polyps was detected during administration. It was measured with using a chemiluminescence analyzer $\left(\mathrm{NIOX}^{\bullet}\right.$ MINO analyzer; Aerocrine $^{\oplus} \mathrm{AB}$, Sweden). The nNO measurements of the patients were made in the off-season time (October-December) at around 9-10 a.m. using the same analyzer as the respiratory method described as resting for $30 \mathrm{~min}$. The analysis was made by confirming that the patients did not drink alcohol for at least $4 \mathrm{~h}$ before the test, that women did not take any food supplements containing Larginine or a nitrate-rich or nitrate-restricted diet, and that there were no signs of infection.

\section{Statistical analysis}

Statistical analysis was conducted using the SPSS software version 23.0 (SPSS, Inc., Chicago, Illinois). Variables were analyzed using visual and analytical methods to determine if they were normally distributed. Mean and standard deviation or median and interquartile ranges were used for descriptive statistics; also, number and \% were used for categorical variables. Chi-square test was used to compare nominal and categorical variables. Parametric data were compared using $T$ test and non-parametric data with Mann-Whitney $U$ test.
Correlation analysis was applied using Spearman and Pearson tests according to distribution. A two-sided $p$ value $<0.05$ was considered statistically significant.

Also, four group analysis was performed according to whether the patients had asthma or not. Mean values of variables with normal distribution were tested with oneway ANOVA test, and abnormally distributed variables were analyzed with Kruskal-Wallis test. According to Bonferroni correction in post hoc analysis, the value was taken as 0.0125 . When general importance was observed, Tukey and Tamhane post hoc tests were performed according to the homogeneity analysis of the variances.

\section{Results}

A total of 443 patients $(277 \mathrm{~F} / 166 \mathrm{M})$; 337 with AR (76\%) and 106 with NAR (24\%) were evaluated. All patients underwent a stepwise diagnostic approach according to the ARIA, resulting in the following subgroups: AR only, NAR only, AR+asthma, and NAR+asthma. The clinical and demographic features of groups were shown in Table 2.

Although patients with AR were significantly younger than non-allergic patients, the duration of rhinitis was significantly longer (5 year, 3 year) $(p=0.037)$. Moreover, allergic patients had more intermittent, moderate to severe disease (> 60\%). Of 337 patients with AR and 106 patients with NAR, asthma comorbidity was found to be $14.4 \%$ and $12.3 \%$, respectively $(p=0.789)$ with no differences between the study groups. In allergic rhinitis, group 3 were positive with latex, 13 with cat-dog, 22 with mold, 24 with blatella, 75 with mite, and the rest with pollen.

Patients with AR had significantly higher nNO levels compared to NAR (370 ppb vs $290 \mathrm{ppb)}(p=0.001)$. When the patients were evaluated according to their gender, female subjects in the AR group had significantly higher nNO than NAR group (370 ppb vs $302 \mathrm{ppb}, p=$ 0.006). Likewise, significant differences were observed in patients with $B M I \geq 25 \mathrm{~kg} / \mathrm{m}^{2}$ and those without sinusitis between the two groups (Table 3). Also, comparison of nNO in study groups was shown in Fig. 1.

As the presence of asthma comorbidity in rhinitis is an important factor, the results were further analyzed in 4 groups (Table 4). Patients with AR w/o asthma had not only the highest TNSS but also had significantly higher nNO level $(p<0.001)$. It was observed that NAR+A

Table 1 Four-point scale used to evaluate the severity of nasal symptoms in study groups

\begin{tabular}{ll}
\hline Score description & \\
\hline 0 None & No sign or symptom evident \\
1 Mild & Sign or symptom clearly present but minimal awareness; easily tolerated \\
2 Moderate & Definite awareness of sign or symptom which is bothersome but tolerable \\
3 Severe & Sign or symptom is hard to tolerate; causes interference with activities of daily living and/or sleeping \\
\hline
\end{tabular}


Table 2 Demographic and clinical characteristics of study groups (AR-NAR)

\begin{tabular}{|c|c|c|c|}
\hline Variables & AR $(n, 337)$ & NAR $(n, 106)$ & $P$ value \\
\hline \multicolumn{4}{|l|}{ Gender, $n(\%)$} \\
\hline $\mathrm{F}$ & $197(58.5)$ & $80(75.5)$ & $0.002^{*}$ \\
\hline M & $140(41.5)$ & $26(24.5)$ & \\
\hline Age, years & $25(20-33)$ & $28(22-39)$ & $0.004^{\#}$ \\
\hline $\mathrm{BMI}\left(\mathrm{kg} / \mathrm{m}^{2}\right)$ & $23.7 \pm 4.3$ & $24.1 \pm 4.3$ & 0.466 \\
\hline $\mathrm{BMI} \geq 25, n(\%)$ & $111(32.9)$ & $39(36.8)$ & $0.465^{*}$ \\
\hline $\mathrm{BMI}<25, n(\%)$ & $226(67.1)$ & $67(63.2)$ & \\
\hline Smoker, $n(\%)$ & $7(2.1)$ & $3(2.8)$ & $0.099^{*}$ \\
\hline Non-smoker & $283(84.7)$ & $97(91.5)$ & \\
\hline Ex-smoker & $44(13.2)$ & $6(5.7)$ & \\
\hline W asthma & $48(14.4)$ & $13(12.3)$ & $0.789^{*}$ \\
\hline TNSS & $6.7 \pm 2.98$ & $5.3 \pm 2.57$ & $<0.001$ \\
\hline Rhinitis duration (year) & $5(2-9)$ & $3(2-10)$ & $0.037^{\#}$ \\
\hline \multicolumn{4}{|l|}{ Severity of rhinitis, $n(\%)$} \\
\hline Mild & $126(37.4)$ & $64(60.4)$ & $<0.001^{*}$ \\
\hline Moderate-severe & $211(62.6)$ & $42(39.6)$ & \\
\hline W sinusitis & $146(43.3)$ & $48(45.3)$ & $0.723^{*}$ \\
\hline \multicolumn{4}{|l|}{ Rhinitis characteristic } \\
\hline Persistent & $99(29.4)$ & $84(79.2)$ & $<0.001^{*}$ \\
\hline Intermittent & $217(64.4)$ & $15(14.2)$ & \\
\hline Persisten+Intermittent & $21(6.2)$ & $7(6.6)$ & \\
\hline \multicolumn{4}{|l|}{ Sensitization } \\
\hline Monosensitization & 265 (78.6) & - & \\
\hline Polisensitization & $72(21.4)$ & - & \\
\hline
\end{tabular}

$F$ female, $M$ male, $A R$ allergic rhinitis, NAR non-allergic rhinitis, $B M I$ body mass index, TNSS total nasal symptoms score, $W$ with, ${ }^{*}$ Chi-square test, "MannWhitney $U$ test, \pm standard deviation, $n$ individual number, $P<0.05$ statistical significance
Table 3 NO levels according to demographic variables in AR and NAR

\begin{tabular}{llll}
\hline & AR & NAR & $P$ value \\
\hline NO level, ppb & $370(199-556)$ & $290(117-442)$ & $0.001^{\#}$ \\
$\mathrm{~F}$ & $370(228-546)$ & $302(122-451)$ & 0.006 \\
$\mathrm{M}$ & $371(185-557)$ & $257(109-402)$ & 0.060 \\
$\mathrm{BMI} \geq 25 \mathrm{~kg} / \mathrm{m}^{2}(111-39)$ & $410(187-590)$ & $250(106-383)$ & 0.008 \\
$\mathrm{BMl}<25 \mathrm{~kg} / \mathrm{m}^{2}(57-16)$ & $356(204-545)$ & $307(121-453)$ & 0.045 \\
Sinusitis, yes (146-48) & $356(185-568)$ & $277(104-505)$ & 0.081 \\
Sinusitis, no (191-58) & $385(220-529)$ & $295(117-386)$ & 0.003 \\
\hline
\end{tabular}

Analysis was performed with the Mann-Whitney $U$ test and the data were presented as median and interquartile values, $F$ female, $M$ male, $A R$ allergic rhinitis, NAR non-allergic rhinitis, $p<0.05$ statistical significance group-with the longest duration of rhinitis-was significantly older and had the lowest nNO level. No differences were observed regarding BMI and TNSS with in the study groups.

Significant relationships were observed between $\mathrm{nNO}$ levels and variables. Nasal NO was significantly correlated with rhinitis duration and TNSS $(r=-0.098, r=$ $0.111 ; p=0.036, p=0.02$, respectively) (Fig. 2). When analyzed separately, $\mathrm{nNO}$ was inversely related with increased age $(r=-0.21, p=0.03)$ only in NAR group. Subgroup analysis of AR patients showed that $\mathrm{nNO}$ levels measured during the season showed significant difference from off-season values (414 ppb vs $270 \mathrm{ppb}$ ) $(p<0.001)$.

Since the duration and severity of rhinitis, as well as the nasal symptoms of our patients showed some differences, we decided to evaluate the effect of the results in two groups comparatively by applying a logistic regression model for all these variables (sex, age, smoking habits, BMI, asthma onset, various allergen sensitizations, rhinitis duration, rhinitis severity, nasal symptoms). Although linear and logistic regression models were applied to assess between various outcomes, we could not find any relationship in tested results.

\section{Discussion}

Because the diagnosis and therapeutic management of allergic airways disease requires monitoring of inflammation as precisely as possible, we tested whether nasal NO could be a reliable AR-NAR discriminator. The idea of nNO measurement is based on "one airway - one disease" concept. Even though asthma and allergic rhinitis vary with the clinical phenotype, Th1/Th2 signaling, main cellular, and biochemical profile, they share the main pathogenetic features [15]. One of them is eosinophilic inflammation that increases the expression of inducible NO synthase (iNOS), leading to increased production of nitric oxide [16]. Therefore, exhaled NO in asthma is a well-defined indicator but studies about $\mathrm{nNO}$ as a marker of allergic rhinitis share conflicting evidence [7].

The aim of this study was to investigate nNO levels and the factors affecting the patients with different etiologies (allergic vs non-allergic). In addition, we evaluated the effect of comorbid asthma in eosinophilic airway inflammation with nNO measurement. Takeno et al. found that generally higher nNO levels are produced in the nasal epithelial cells of allergic patients through co-expression of different isoforms (iNOS and endothelial NOS) [17]. In our present study, patients with AR were found to have significantly higher $\mathrm{nNO}$ levels compared to NAR consistent with the previous reports. Moody et al. found that $\mathrm{nNO}$ levels were higher in allergic patients but were not elevated in perennial 


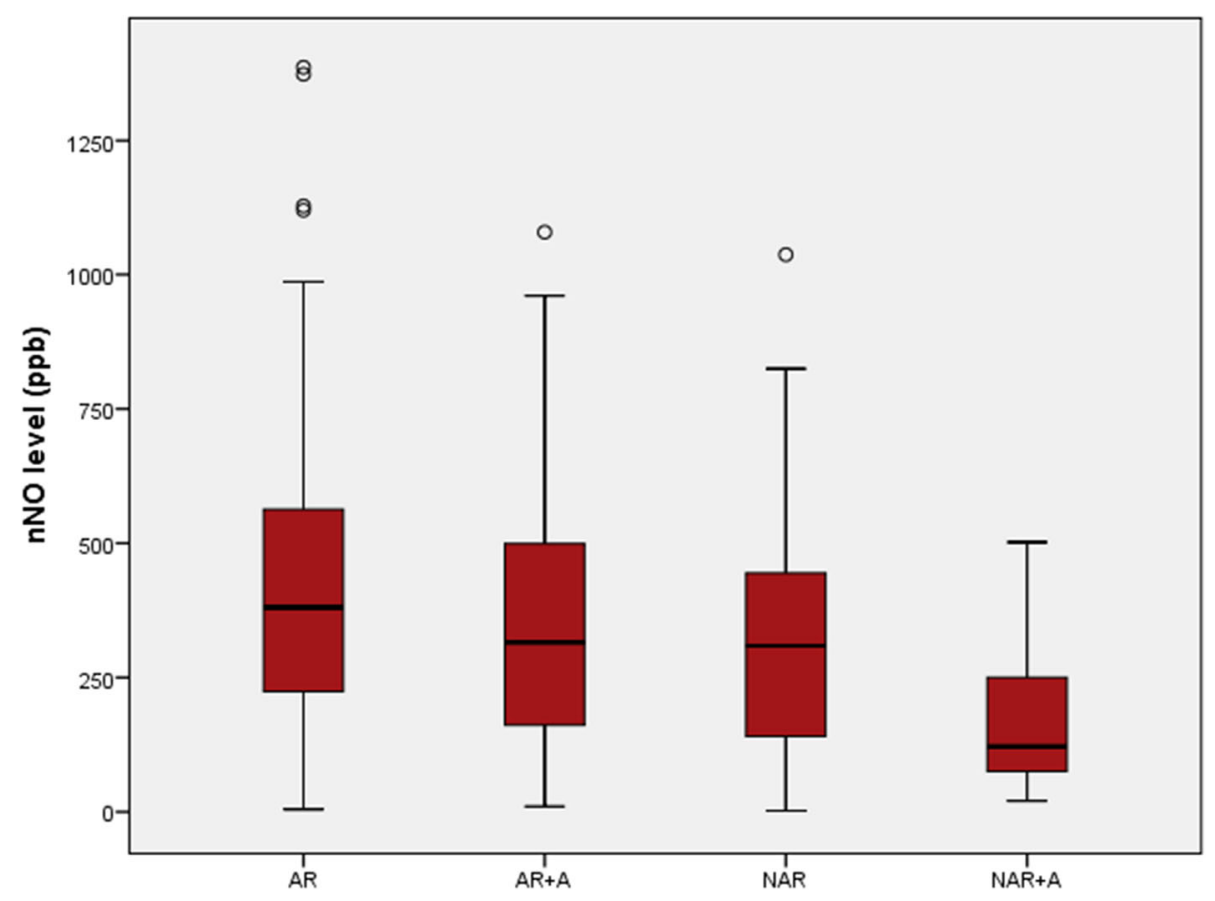

Fig. 1 Comparison of $\mathrm{nNO}$ in study groups

rhinitis, as was found in our study (results not shown) [18]. It is known that nasal NO was higher in AR patients, but in those studies, $\mathrm{nNO}$ was compared with the control group. As was speculated by Liu et al., different pathogenetic mechanisms of neurogenic inflammation in NAR and IgE-mediated inflammation in AR may probably be responsible for different $\mathrm{nNO}$ levels [19].

In a study performed by Martina et al. who examined $\mathrm{FeNO}$ and $\mathrm{nNO}$, gender-related differences were found in the FeNO, but not in the nNO levels neither for control nor for allergic rhinitis groups [20]. In consistent with the literature, when our patients were evaluated according to their gender, female subjects in the AR group had significantly higher $\mathrm{nNO}$ levels compared to those of NAR group, but no such difference was found within the groups. The higher $\mathrm{nNO}$ in female gender in AR suggests the production and role of this biomarker other than IgE-mediated inflammation, as it can be a consequence of different sensitivity of NO synthase isoforms to estrogen [21].

It is widely known that asthma and AR often coexist in the same subjects [22]. Approximately $80 \%$ of patients with asthma are affected by AR and $10-40 \%$ of AR subjects have asthma [23]. In a study conducted by Gupta et al., it was determined that the adult patient group with bronchial asthma and AR had a higher nNO level compared to the control group [24]. It was also stated that these patients had higher nNO levels compared to AR patients, but their findings were not statistically significant. On the other hand, in another study, a significant difference was observed in the $\mathrm{nNO}$ level measured using an electrochemical analyzer [25]. Sergei et al. found that in patients with rhinitis accompanied by asthma who were not receiving nasal or inhaled steroid therapy, nNO was significantly elevated [26]. Despite these conflicting results in our study, although no

Table 4 Characteristics of the study groups according to comorbid asthma

\begin{tabular}{llllll}
\hline & AR $(\boldsymbol{n}, \mathbf{2 8 9})$ & AR+A $(\boldsymbol{n}, \mathbf{4 8})$ & NAR $(\boldsymbol{n}, \mathbf{9 3})$ & NAR+A $(\boldsymbol{n}, \mathbf{1 3})$ & $\boldsymbol{P}$ value \\
\hline Age & $25(21-33)$ & $27(20-35)$ & $27(21-35)$ & $45(32-58)$ & $\mathbf{0 . 0 0 1 ^ { \# }}$ \\
BMI & $23.8 \pm 4.4$ & $23.3 \pm 4.4$ & $23.8 \pm 4.4$ & $23.8 \pm 4.4$ & $0.121^{*}$ \\
TNSS & $6.8 \pm 3.01$ & $6.4 \pm 2.7$ & $5.4 \pm 2.6$ & $5.1 \pm 2.4$ & $0.064^{*}$ \\
Rhinitis duration (year) & $5(2-9)$ & $5(3-10)$ & $3(2-7)$ & $9(2-21)$ & $0.013^{\#}$ \\
nNO & $380(223-565)$ & $315(159-504)$ & $309(135-445)$ & $121(69-254)$ & $<0.001^{\#}$ \\
\hline
\end{tabular}

$A R$ allergic rhinitis, NAR non-allergic rhinitis, $A R+A$ allergic rhinitis + asthma, NAR+A non-allergic rhinitis + asthma, $B M I$ body mass index, TNSS total nasal symptoms score, *One-way ANOVA test, "Kruskal-Wallis test, according to post hoc analysis, $p$ values in bold are significant 

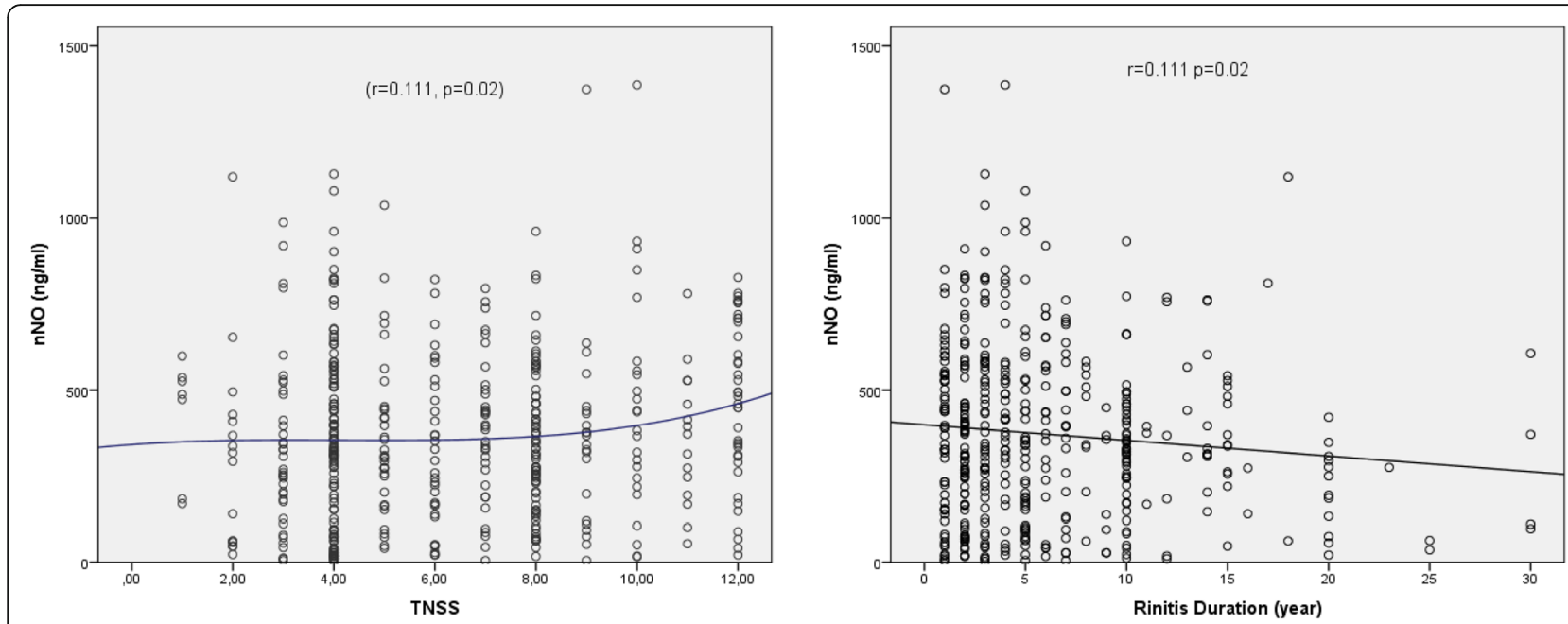

Fig. 2 Correlation between nNO, TNSS, and rhinitis duration

significant difference was found between $A R$ and $A R+A$ groups, $\mathrm{nNO}$ level was found to be significantly lower in the NAR group with comorbid asthma. Although most of our allergic patients were sensitized with seasonal allergens, i.e., pollens, those with $\mathrm{AR}+\mathrm{A}$ had on regular inhaled steroid treatment, all-year round, may have lowered nNO levels. In order to optimize our study, we had measured nNO levels in patients who were followed-up for at least 6 months, which leads to the fact that non-allergic rhinitis with asthma regularly took inhaled steroid therapy, as well. Another explanation of the lower nNO in NAR patients with asthma may also be due to relatively small number of this subgroup.

Nasal NO was higher in AR patients without being affected by BMI, comorbid asthma, and/or sinusitis. However, the low nNO levels in NAR patients were more pronounced in higher BMI, inversely correlated with comorbid asthma and/or sinusitis, suggest that nNO can be affected by many factors.

Nasal NO is affected by season, time points of the day, physical exercise, respiratory method, and analyzers [2730]. Most of the published articles have not fully identified or made any effort to control the above external factors. This not only magnifies the alteration in a single study but also leads to a lack of comparability between different studies. To minimize the variation caused by these factors, the current study was handled by the same qualified technician who performed all measurements of nNO using the same analyzer at the same time of the day after the participants rest for at least $30 \mathrm{~min}$.

An important limitation of our study was the lack of control group, as we specifically aimed to compare allergic and non-allergic patients with rhinitis. We did not perform paranasal CT in the patients because paranasal CT did not have a place in the clinic in the distinction of AR-NAR, and the lack of routine endoscopic nasal examination was another limitation of the study.

Although $\mathrm{nNO}$ was studied previously in AR patients, to our knowledge, this study is the first one to show a significant difference between AR and NAR with or without asthma. Nasal NO may be valuable in distinguishing between allergic rhinitis as we found a significant difference compared to NAR group. nNO could be accepted as a reliable biomarker and a validated tool for the measurement of eosinophilic airway inflammation. Further studies regarding nNO and its relation to allergic and non-allergic inflammation of upper/lower airways are warranted.

\section{Conclusion}

Nasal NO has not been adequately studied in upper airways. We found that $\mathrm{nNO}$ was significantly higher in AR patients than NAR. Although the standardization of nNO levels is difficult due to the various factors that it is cheap, painless, and fast, we think that our results seem to be sufficient to distinguish between these two diseases. We recommend that measurement of nasal nitric oxide is not only sufficient to distinguish between $\mathrm{AR}$ and NAR but also an applicable tool in clinical practice.

\section{Abbreviations}

AR: Allergic rhinitis; AR+A: Allergic rhinitis + asthma; BMI: Body mass index; F: Female; FeNO: Fractional exhaled nitric oxide; iNOS: Inducible nitric oxide synthase; M: Male; NAR: Non-allergic rhinitis; NAR+A: Non-allergic rhinitis + asthma; nNo: Nasal nitric oxide; SPTs: Skin prick tests; TNSS: Total nasal symptom score

Acknowledgements

None 


\section{Authors' contributions}

Concept and design of study: FK, AB, SAY. Analysis and interpretation of data: $F K, A B, S A Y$. Drafting and critical revision: FK, AB, SAY. All authors read and approved the final version of the manuscript.

\section{Funding}

The study did not have any supporters.

\section{Availability of data and materials}

The datasets used and analyzed during the current study are available from the corresponding author on reasonable request.

\section{Declarations}

\section{Ethics approval and consent to participate}

The study protocol complied with the ethical principles of the Declaration of Helsinki and received full approval from the institutional review boards of Institutional Kirikkale University Ethics Committee (No: 24/05, Date: 20.10.2014). Verbal informed consents were obtained from all participants or their parents in the case of children under 16 years.

\section{Consent for publication}

Not applicable.

\section{Competing interests}

The authors declare that they have no competing interests regarding the publication of this paper.

Received: 7 July 2021 Accepted: 7 August 2021

Published online: 16 September 2021

\section{References}

1. Bousquet J, Fokkens W, Burney P, Durham SR, Bachert C, Akdis CA, Canonica GW, Dahlen SE, Zuberbier T, Bieber T, Bonini S, Bousquet PJ, Brozek JL, Cardell LO, Crameri R, Custovic A, Demoly P, van Wijk RG, Gjomarkaj M, Holland C, Howarth P, Humbert M, Johnston SL, Kauffmann F, Kowalski ML, Lambrecht B, Lehmann S, Leynaert B, Lodrup-Carlsen K, Mullol J, Niggemann B, Nizankowska-Mogilnicka E, Papadopoulos N, Passalacqua G, Schünemann HJ, Simon HU, Todo-Bom A, Toskala E, Valenta R, Wickman M, Zock JP (2008) Important research questions in allergy and related diseases: nonallergic rhinitis: a GA2LEN paper. Allergy. 63(7):842-853. https://doi.org/1 0.1111/j.1398-9995.2008.01715.x

2. Ignarro LJ, Buga GM, Wood KS, Byrns RE, Chaudhuri G (1987) Endotheliumderived relaxing factor produced and released from artery and vein is nitric oxide. Proc Natl Acad Sci 84(24):9265-9269. https://doi.org/10.1073/pnas. 84.24 .9265

3. Montoro J, Del Cuvillo A, Mullol J et al (2012) Validation of the modified allergic rhinitis and its impact on asthma (ARIA) severity classification in allergic rhinitis children: the PEDRIAL study. Allergy. 67(11):1437-1442. https://doi.org/10.1111/all.12011

4. Kalpaklioglu AF, Kavut AB (2009) Allergic and nonallergic rhinitis: can we find the differences/similarities between the two pictures? J Asthma 46(5): 481-485. https://doi.org/10.1080/02770900902849897

5. El Gustafsson L, Leone AM, Persson MG, Wiklund NP, Moncada S (1991) Endogenous nitric oxide is present in the exhaled air of rabbits, guinea pigs and humans. Biochem Biophys Res Commun 181(2):852-857. https://doi. org/10.1016/0006-291X(91)91268-H

6. Alving K, Janson C, Nordvall L (2006) Performance of a new hand-held device for exhaled nitric oxide measurement in adults and children. Respir Res $7(1): 1-7$

7. Lee KJ, Cho SH, Lee SH, Tae K, Yoon HJ, Kim SH, Jeong JH (2012) Nasal and exhaled nitric oxide in allergic rhinitis. Clin Exp Otorhinolaryngol 5(4):228233. https://doi.org/10.3342/ceo.2012.5.4.228

8. Kawamoto H, Takeno S, Yajin K (1999) Increased expression of inducible nitric oxide synthase in nasal epithelial cells in patients with allergic rhinitis. Laryngoscope 109(12):2015-2020. https://doi.org/10.1097/00005537-199912 000-00023

9. Kulkarni AP, Getchell TV, Getchell ML (1994) Neuronal nitric oxide synthase is localized in extrinsic nerves regulating perireceptor processes in the chemosensory nasal mucosae of rats and humans. J Comp Neurol 345(1): 125-138. https://doi.org/10.1002/cne.903450110
10. Kalpaklioglu AF, Kalkan IK (2012) Comparison of orally exhaled nitric oxide in allergic versus nonallergic rhinitis. Am J Rhinol Allergy 26(2):e50-e54. https://doi.org/10.2500/ajra.2012.26.3717

11. (2019) Issue Information-Declaration of Helsinki. J Bone Miner Res Off J Am Soc Bone Miner Res 34(3):BMi-BMii

12. Reddel HK, Levy ML (2015) The GINA asthma strategy report: what's new for primary care? NPJ Prim Care Respir Med 25(1):1-4

13. Albataineh $\mathrm{E}, \mathrm{Al}$-Zayadneh $\mathrm{E}, \mathrm{Al}$-Shagahin $\mathrm{H}$ et al (2019) Asthma control and its predictive factors in adult asthma patients. J Clin Med Res 11(12):807817. https://doi.org/10.14740/jocmr4021

14. Tamasauskiene L, Gasiuniene E, Sitkauskiene B (2021) Translation, adaption and validation of the total nasal symptom score (TNSS) for Lithuanian population. Health Qual Life Outcomes 19(1):54. https://doi.org/10.1186/s12955-020-01659-8

15. Bachert C, Khaltaev N (2002) Allergic rhinitis and its impact on asthma. In collaboration with the World Health Organization. Executive summary of the workshop report. 7-10 December 1999, Geneva, Switzerland. Allergy 57(9):841-855. https://doi.org/10.1034/j.1398-9995.2002.23625.x

16. Williamson PA, Vaidyanathan S, Clearie K, Stewart M, Lipworth BJ (2010) Relationship between fractional exhaled nitric oxide and nasal nitric oxide in airways disease. Ann Allergy Asthma Immunol 105(2):162-167. https://doi. org/10.1016/j.anai.2010.05.014

17. Takeno S, Osada R, Furukido K, Chen JH, Yajin K (2001) Increased nitric oxide production in nasal epithelial cells from allergic patients-RT-PCR analysis and direct imaging by a fluorescence indicator: DAF-2 DA. Clin Exp Allergy 31(6):881-888. https://doi.org/10.1046/j.1365-2222.2001.01093.x

18. Moody A, Fergusson W, Wells A, Bartley J, Kolbe J (2006) Nasal levels of nitric oxide as an outcome variable in allergic upper respiratory tract disease: influence of atopy and hayfever on nNO. Am J Rhinol 20(5):425429. https://doi.org/10.2500/ajr.2006.20.2921

19. Liu C, Zheng K, Liu X et al (2020) Use of nasal nitric oxide in the diagnosis of allergic rhinitis and nonallergic rhinitis in patients with and without sinus inflammation. J Allergy Clin Immunol Pract 8(5):1574-1581.e4. https://doi. org/10.1016/j.jaip.2019.12.017

20. Antosova M, Bencova A, Mokra D, Plevkova J, Pepucha L, Buday T (2020) Exhaled and nasal nitric oxide-impact for allergic rhinitis. Physiol Res 69(Suppl 1):S123-S130. https://doi.org/10.33549/physiolres.934393

21. Yuksel H, Kirmaz C, Yilmaz O, Pinar E, Vatansever S, Degirmenci PB, Ozbilgin K (2008) Nasal mucosal expression of nitric oxide synthases in patients with allergic rhinitis and its relation to asthma. Ann Allergy Asthma Immunol 100(1):12-16. https://doi.org/10.1016/S1081-1206(10)60398-5

22. Bousquet J, Schünemann HJ, Samolinski B, Demoly P, Baena-Cagnani CE, Bachert C, Bonini S, Boulet LP, Bousquet PJ, Brozek JL, Canonica GW, Casale TB, Cruz AA, Fokkens WJ, Fonseca JA, van Wijk RG, Grouse L, Haahtela T, Khaltaev N, Kuna P, Lockey RF, Lodrup Carlsen KC, Mullol J, Naclerio R, O'Hehir RE, Ohta K, Palkonen S, Papadopoulos NG, Passalacqua G, Pawankar R, Price D, Ryan D, Simons FER, Togias A, Williams D, Yorgancioglu A, Yusuf OM, Aberer W, Adachi M, Agache I, Aït-Khaled N, Akdis CA, Andrianarisoa A, Annesi-Maesano I, Ansotegui IJ, Baiardini I, Bateman ED, Bedbrook A, Beghé B, Beji M, Bel EH, Ben Kheder A, Bennoor KS, Bergmann KC, Berrissoul F, Bieber T, Bindslev Jensen C, Blaiss MS, Boner AL, Bouchard J, Braido F, Brightling CE, Bush A, Caballero F, Calderon MA, Calvo MA, Camargos PAM, Caraballo LR, Carlsen KH, Carr W, Cepeda AM, Cesario A, Chavannes NH, Chen YZ, Chiriac AM, Chivato Pérez T, Chkhartishvili E, Ciprandi G, Costa DJ, Cox L, Custovic A, Dahl R, Darsow U, de Blay F, Deleanu D, Denburg JA, Devillier P, Didi T, Dokic D, Dolen WK, Douagui H, Dubakiene R, Durham SR, Dykewicz MS, el-Gamal Y, el-Meziane A, Emuzyte R, Fiocchi A, Fletcher M, Fukuda T, Gamkrelidze A, Gereda JE, González Diaz S, Gotua M, Guzmán MA, Hellings PW, Hellquist-Dahl B, Horak F, Hourihane JO'B, Howarth P, Humbert M, Ivancevich JC, Jackson C, Just J, Kalayci O, Kaliner MA, Kalyoncu AF, Keil T, Keith PK, Khayat G, Kim YY, Koffi N'Goran B, Koppelman GH, Kowalski ML, Kull I, Kvedariene $V$, Larenas-Linnemann $D$, le LT, Lemière C, Li J, Lieberman P, Lipworth B, Mahboub B, Makela MJ, Martin F, Marshall GD, Martinez FD, Masjedi MR, Maurer M, Mavale-Manuel S, Mazon A, Melen E, Meltzer EO, Mendez NH, Merk H, Mihaltan F, Mohammad Y, Morais-Almeida M, Muraro A, Nafti S, Namazova-Baranova L, Nekam K, Neou A, Niggemann B, Nizankowska-Mogilnicka E, Nyembue TD, Okamoto Y, Okubo K, Orru MP, Ouedraogo S, Ozdemir C, Panzner P, Pali-Schöll I, Park HS, Pigearias B, Pohl W, Popov TA, Postma DS, Potter P, Rabe KF, Ratomaharo J, Reitamo S, Ring J, Roberts R, Rogala B, Romano A, Roman Rodriguez M, Rosado-Pinto J, Rosenwasser L, Rottem M, Sanchez-Borges M, Scadding GK, SchmidGrendelmeier P, Sheikh A, Sisul JC, Solé D, Sooronbaev T, Spicak V, Spranger 
O, Stein RT, Stoloff SW, Sunyer J, Szczeklik A, Todo-Bom A, Toskala E, Tremblay Y, Valenta R, Valero AL, Valeyre D, Valiulis A, Valovirta E, van Cauwenberge $P$, Vandenplas $\mathrm{O}$, van Weel C, Vichyanond P, Viegi G, Wang DY, Wickman M, Wöhrl S, Wright J, Yawn BP, Yiallouros PK, Zar HJ, Zernott ME, Zhong N, Zidarn M, Zuberbier T (2012) Allergic rhinitis and its impact on asthma (ARIA): achievements in 10 years and future needs. J Allergy Clin Immunol 130(5):1049-1062. https://doi.org/10.1016/j.jaci.2012.07.053

23. Leynaert B, Neukirch F, Demoly P, Bousquet J (2000) Epidemiologic evidence for asthma and rhinitis comorbidity. J Allergy Clin Immunol 106(5): S201-S205. https://doi.org/10.1067/mai.2000.110151

24. Gupta N, Goel N, Kumar R (2014) Correlation of exhaled nitric oxide, nasal nitric oxide and atopic status: a cross-sectional study in bronchial asthma and allergic rhinitis. Lung India Off Organ Indian Chest Soc 31(4):342

25. Takeno S, Noda N, Hirakawa K (2012) Measurements of nasal fractional exhaled nitric oxide with a hand-held device in patients with allergic rhinitis: relation to cedar pollen dispersion and laser surgery. Allergol Int 61(1):93-100. https://doi.org/10.2332/allergolint.11-OA-0318

26. Kharitonov SA, Rajakulasingam K, O'Connor B, Durham SR, Barnes PJ (1997) Nasal nitric oxide is increased in patientswith asthma and allergic rhinitis and may be modulated by nasal glucocorticoids. J Allergy Clin Immunol 99(1, Part 1):58-64. https://doi.org/10.1016/S0091-6749(97)81045-7

27. Stark H, Purokivi M, Kiviranta J, Randell J, Tukiainen H (2007) Short-term and seasonal variations of exhaled and nasal NO in healthy subjects. Respir Med 101(2):265-271. https://doi.org/10.1016/j.rmed.2006.05.009

28. Kharitonov S, Alving K, Barnes PJ (1997) Exhaled and nasal nitric oxide measurements: recommendations. The European Respiratory Society Task Force. Eur Respir J 10(7):1683-1693. https://doi.org/10.1183/09031936.97.1 0071683

29. Lundberg JO, Rinder J, Weitzberg F, Alving K, Lundberg JM (1997) Heavy physical exercise decreases nitric oxide levels in the nasal airways in humans. Acta Physiol Scand 159(1):51-57. https://doi.org/10.1046/j.1365-201 X.1997.68339000.x

30. Marthin JK, Nielsen KG (2013) Hand-held tidal breathing nasal nitric oxide measurement--a promising targeted case-finding tool for the diagnosis of primary ciliary dyskinesia. PLoS One 8(2):e57262. https://doi.org/10.1371/ journal.pone.0057262

\section{Publisher's Note}

Springer Nature remains neutral with regard to jurisdictional claims in published maps and institutional affiliations.

\section{Submit your manuscript to a SpringerOpen ${ }^{\circ}$ journal and benefit from:}

- Convenient online submission

- Rigorous peer review

- Open access: articles freely available online

- High visibility within the field

- Retaining the copyright to your article

Submit your next manuscript at $\boldsymbol{\nabla}$ springeropen.com 